\title{
Incipient motion of sediment particles in the presence of bed forms under decelerating and accelerating flows
}

\author{
Esmaeil Dodangeh, Hossein Afzalimehr ${ }^{*}$ \\ Natural Disasters Prevention Research Center, School of Civil Engineering, Iran University of Science and Technology, Tehran, Iran. \\ * Corresponding author. Tel.: (+98-21) 77240565 Ex: 8131. E-mail: hafzali@iust.ac.ir
}

\begin{abstract}
This paper investigates the incipient motion of sediment particles under non-uniform flow in river and laboratory. In rivers, the non-uniform flow is often observed due to the presence of various bed forms. Threshold condition has been examined by using the Shields diagram based on the uniform flow assumption, however, this approach can be led to fallacious results for non-uniform flows where the effect of pressure gradient is significant due to bed forms. This study investigates the chronological order of incipient motion of the particles, the average threshold velocity $\left(U_{c r}\right)$, and Shields parameter for non-uniform flows. River data collection with gravel is used for investigating the incipient motion of surface layer of river bed and the laboratory data collection is considered studying the incipient motion of sub-surface layer of river. Both river and laboratory data collections are conducted in the presence of bed forms. Results reveal that the Shields diagram underestimates the particle incipient motion under accelerating and decelerating flows for the both case of laboratory and river. In both weak and general motion in the laboratory, the values of the critical Shields parameter are located below the Shields diagram, showing no particle motion. Our analysis shows that the incipient motion in river is affected by the presence of bed forms, river width changes, and flow non-uniformity conditions. The results show that in the accelerating flow (the bed form exit with a negative slope), the incipient motion is greater than the decelerating flow (the bed form entrance with a positive slope).
\end{abstract}

Keywords: Incipient motion; Bed forms; Accelerating and Decelerating flows; Bed shear stress; Shields parameter.

\section{INTRODUCTION}

The incipient motion of sediment particles is a key element in sediment transport, stable channel design, and precautionary measures against erosion (Church and Hassan, 2005; Dey, 2014; Hassan and Woodsmith, 2004). There are different methods to determine the initial motion of particles, such as visual observation, critical bed shear stress method, and critical flow velocity method. Among these methods, the critical bed shear stress has often been used based on the Shields diagram (Buffington and Montgomery, 1997; Shahmohammadi et al., 2018). On the vertical axis of this diagram, the bed shear stress $\left(\tau_{0}\right)$ is used to calculate Shields dimensionless parameter. Then, the bed shear stress is divided by $\left(\rho_{s}-\rho\right) g d$, where $\rho=$ fluid density; $\rho_{s}=$ sediment density; $g=$ gravitational acceleration and $d=$ grain size, yields the Shields dimensionless parameter $\Theta$. The horizontal axis of the Shields diagram uses the grain Reynolds number $\left(R e_{*}\right)$, which is calculated as $u_{*} k_{\mathrm{S}} / \vartheta$, in which $u_{*}=$ shear velocity; $k_{s}=$ roughness height, and $\vartheta=$ kinematic viscosity of water. Shields (1936) formulated the Shields dimensionless parameter and Rose (1953) diagrammatically showed that the variation of this parameter against different values of the grain Reynolds number. However, Shields' experiments were carried out under uniform flow conditions using laboratory uniform sediment mixture without considering the presence of bed forms (Buffington and Montgomery, 1997), whereas in rivers non-uniform flows form due to the presence of different bed forms and consequently, sediment transport and the initial motion of particles will be different than in uniform flow conditions. In recent years, some studies have been conducted to characterize the interaction of non-uniformity of flow-bed forms on sediment transport (Bolhassani et al., 2015; Emadzadeh et al., 2010; Shahmohammadi et al., 2018). These studies reveal that when the flow is non-uniform, the incipient motion occurs even though the Shields diagram shows no motion. One of the integral factors influencing the incipient motion of sediment particles is the streamwise bed slope. Studies on the effect of longitudinal and transverse slopes on the estimation of critical Shields stress show that critical shear stress is not only a function of the particle Reynolds number but also depends on the longitudinal slope of the bed (Chiew and Parker, 1994; Dey, 2003; Lamb et al., 2008). Luque and Van Beek (1976) experiments showed that the critical shear stress required for the incipient motion of sediment on a longitudinal sloping bed reduces with increase in slope. It instinctively seems that the threshold bed shear stress required to entrain the sediment particles on a streamwise sloping bed would be much smaller than that required on a plane bed due to a considerable decrement of the component of submerged weight in the streamwise direction (Dey and Debnath, 2000; Wiberg and Smith, 1987). The decreased mobility of sediments on a steep streamwise bed slope is mainly attributed to an increase in relative roughness, which is the ratio of bed roughness height $k_{s}$ to flow depth $h\left(=k_{s} / h\right)$. This is due to the fact that for a steady-unidirectional streamflow having a specified bed shear stress, the flow depth is inversely proportional to the streamwise bed slope. Some researchers have suggested different mechanisms to clarify the cause of this phenomenon; for example, an unknown packing factor that raises the slope stability, an increase in momentum loss, a reduction of bed shear stress in the presence of large bed forms and boulders, a reduction of flow velocity in the near-bed flow zone, and a decrease in jamming ratio, which is the ratio of channel width to sediment size (Dey and Ali, 2019). Dey and Debnath (2000) showed that the shear stress values required to move sediment particles significantly depended on bed slope. Emadzadeh et al. (2010) claimed that critical shear stress and 
Shields parameter for the threshold of particle motion in accelerating flow were significantly higher than in decelerating flow. Bolhassani et al. (2015) indicated that the Shields diagram was inappropriate to estimate the critical shear stress under decelerating flow because on the initiation of motion, the critical Shields stress was below the curve. Afzalimehr et al. (2007) examined the effect of decelerating flow on the threshold of motion in a gravel-bed stream. Their results showed that the distribution of shear stress on fixed and mobile beds took on a convex shape, and accordingly, the value of the critical Shields parameter for the decelerating flow was less than the values reported in other studies. In a field study, MacVicar and Roy (2007) examined changes of the velocity distribution and the intensity of turbulence in the presence of a forced riffle pool in a gravel bed river and showed that the maximum velocity position in the velocity profile was near the water surface for decelerating flow and also, $z / Z=0.4$ under the water surface during the accelerating flow. They also noted that there was relatively little knowledge about the effects of this type of bed form on the threshold of motion and sediment transport, especially in non-uniform gravel sediments. The Shields diagram has been prepared for uniform flow, while in rivers due to the presence of different bed forms, the flow is non-uniform. Therefore, the application of the Shields diagram for nonuniform flow requires deeper considerations and research in both field and laboratory scales. The objectives of this study are: 1) to investigate how the values of the critical Shields parameter change with variation in both bed form and sediment size along the selected reaches and the laboratory flume; 2) to investigate how the velocity profile is distributed across the flow depth as well as how the average threshold velocity $\left(U_{c r}\right)$ changes with the variation of bed form along the laboratory flume; 3 ) to study the effect of flow non-uniformity (accelerating and decelerating flows) on incipient motion of sediment particles.

\section{MATERIALS AND METHODS Site selection}

River data were taken from the Deryouk River in this study. The river is located near Namar village, 40 kilometers from Amol city in Mazandaran province in the north of Iran. It is located in the catchment area of Khazar sea, and is one of the branches of Haraz River. Deryouk River originates from Kahoon summit, one of the summits of Alborz mountains, which joins Haraz River by crossing the meandrous and mountainous route, and finally drops in Khazar sea. This river has an average discharge of $2.76 \mathrm{~m}^{3} / \mathrm{s}$. After walking and searching for more than two weeks for finding suitable reaches for collecting data, two reaches approximately 32 and 48 meters in length were selected. Each reach is located in two different parts of the river. The criteria for selecting suitable sites and reaches were the presence of bed forms, suitable flow discharge, safe and suitable width and depth of flow for collecting data without any risk to work. Figure 1 shows the locations of selected reaches in Deryouk River. The first reach had a length of $32 \mathrm{~m}$, variable width between 3.2-6.5 m, and variable flow depth between 15$45 \mathrm{~cm}$; and for the second reach length, width, and depth were $48 \mathrm{~m}, 6.14-9.5 \mathrm{~m}$, and $15-50 \mathrm{~cm}$, respectively. Table 1 shows the characteristics of selected reaches including length, average width, the number of cross sections along the reaches and average discharge. All laboratory data in this study were collected at the Hydraulic Research Institute of Tehran Water Research Center. Experiments were performed on a $45 \mathrm{~cm}$ wide, $1 \mathrm{~m}$ deep and $12 \mathrm{~m}$ long rectangular flume with glass walls. The flume had a closed rotating system in which water was discharged from the tank to the flume by pump.

\section{Flow measurements}

Flow characteristics were measured in 10 cross sections for two reaches, and measurements were done in five cross sections in each reach. The reaches were straight, and the intervals of cross sections from each other were not necessarily equal. In general, 45 velocity profiles were measured for which 12 to 18 point velocity values, on average, were recorded in each one. In this research, a propeller type of current meter made in Iran by a private company was used to measure the flow velocity. Flow velocity at each point has been measured three times and the duration of each repetition was 60 seconds. Velocity profile data were used to determine shear velocity, mean velocity to calculate flow discharge, and other hydraulic parameters. Figure 2 shows the flow velocity measurements by the mechanical current meter.
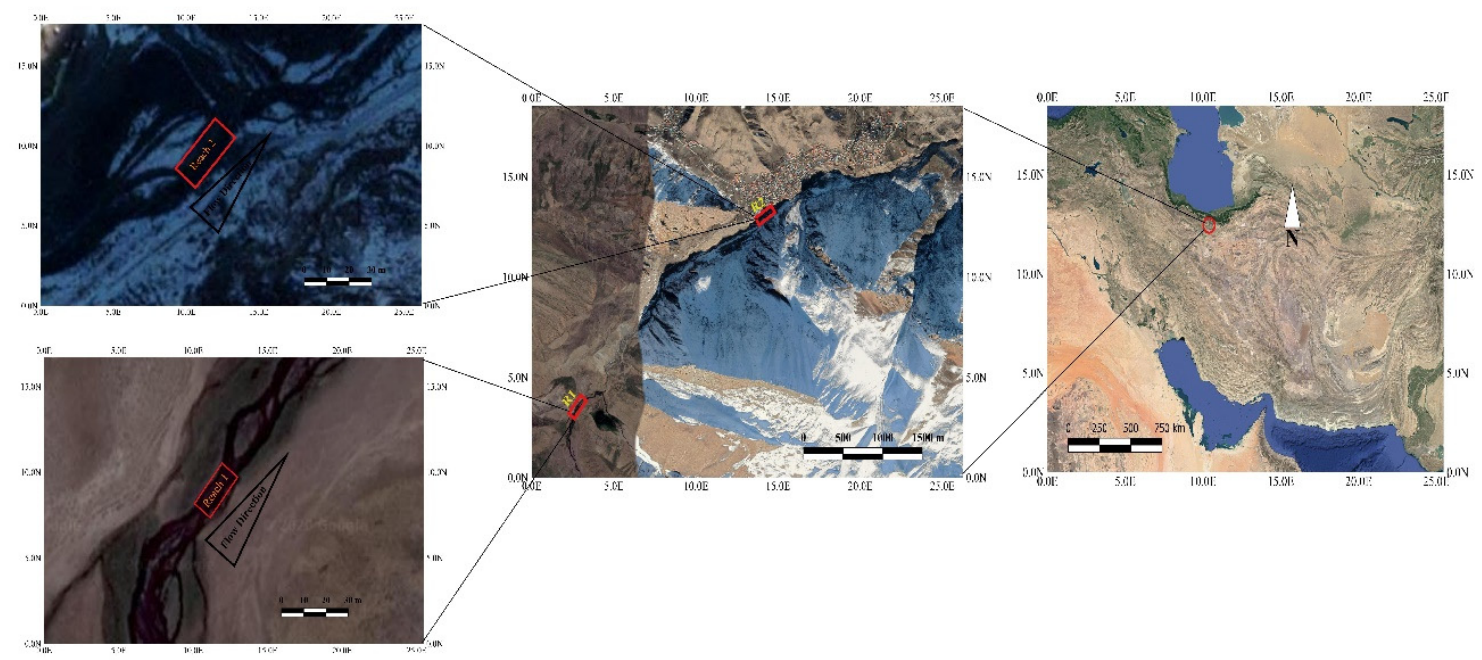

Fig. 1. Geographic location of selected reaches in Deryouk River. 
Table 1. Characteristics of selected reaches.

\begin{tabular}{ccccc}
\hline Reach number & $\begin{array}{c}\text { Length } \\
(\mathrm{m})\end{array}$ & $\begin{array}{c}\text { Average width } \\
(\mathrm{m})\end{array}$ & $\begin{array}{c}\text { Number of cross } \\
\text { sections }\end{array}$ & $\begin{array}{c}\text { Average discharge } \\
\left(\mathrm{m}^{3} / \mathrm{s}\right)\end{array}$ \\
\hline$(1)$ & 48 & $3.2-6.5$ & 5 & 4.32 \\
\hline$(2)$ & 32 & $6.14-9.5$ & 5 & 2.42 \\
\hline
\end{tabular}

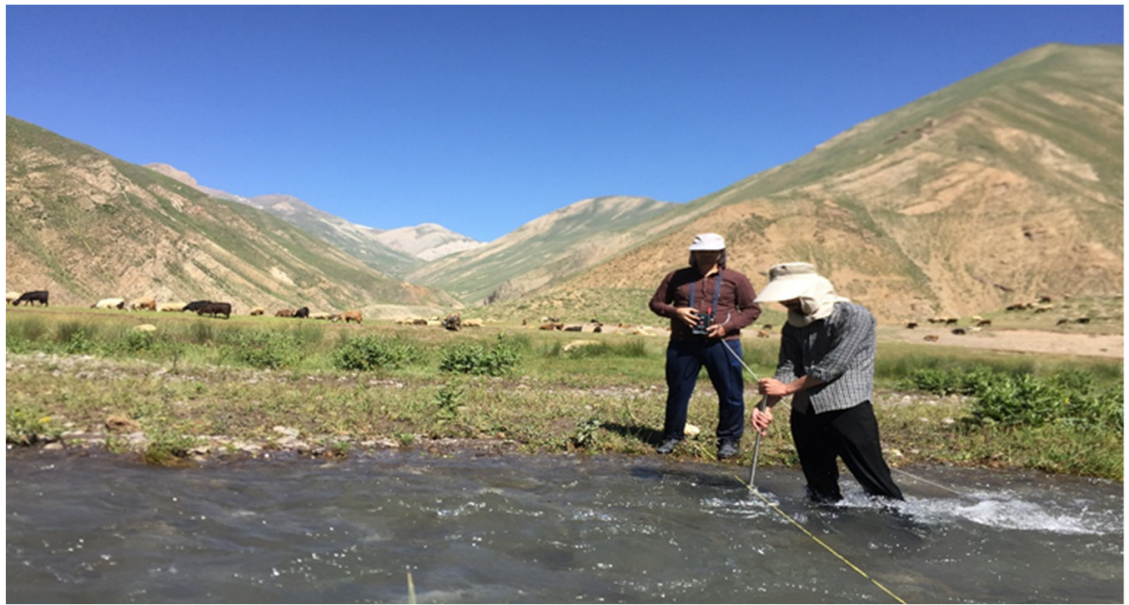

Fig. 2. Flow velocity measurement by the mechanical current meter.

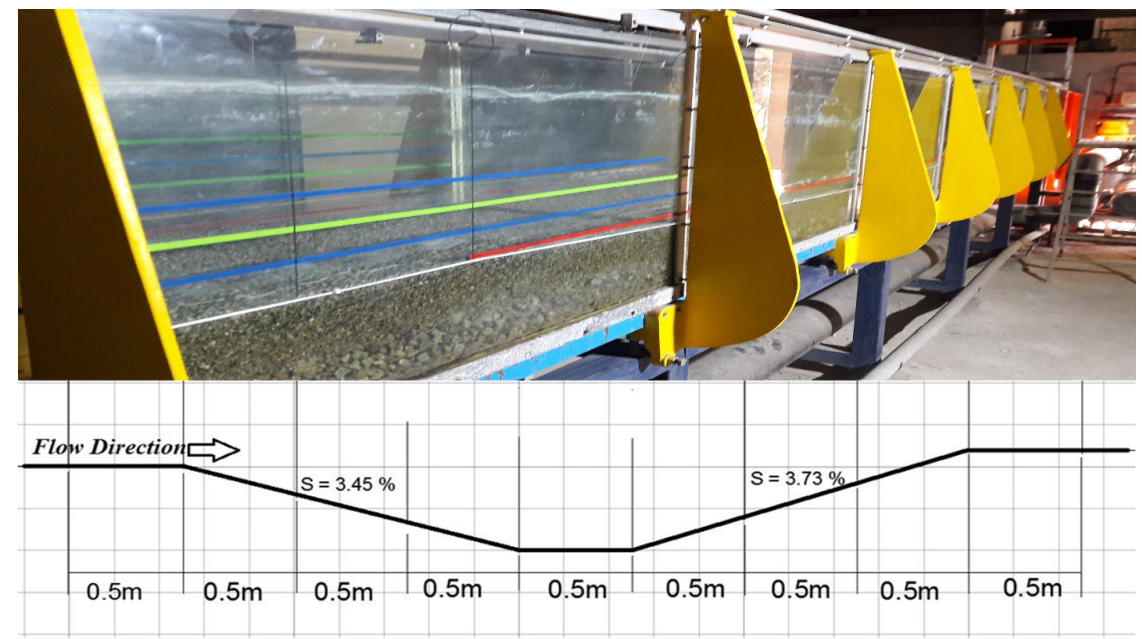

Fig. 3. The experimental flume and the profile of the bed form made in the laboratory.

All data collection was obtained in July 2018. Five velocity profiles were measured in each section, with one profile in the middle of the section, and two profiles on the sides. Granulating operation in this study generally consisted of two parts: 1) Granulating the particles that make up the riverbed using the Wolman pebble counts method 2) Granulating the bed load samples using sieve analysis test. The bed-load was sampled using the Helley-Smith bed-load sampler at three points in each section. One of the sampling points of bed-load was in the middle of the section and two points were on the right and left sides. The Helley-Smith (HS) sampler has an extending nozzle, sample bag, and frame. This sampler was designed for utilizing in flows with mean velocities up to $3 \mathrm{~m} / \mathrm{s}$. The sampler has a square $7.62 \mathrm{~cm}$ entree nozzle and a $46 \mathrm{~cm}$ long sample bag constructed with a $0.25 \mathrm{~mm}$ mesh polyester. The mesh openings in the bag permit water and fine sediment to flow through the bag while trapping the coarse sediment. Bed load sampling time is 120 seconds at each point and in each repetition, which was done by three repetitions at each point. The reason for this is to reduce the possible error in bed load sampling.
Granulating operation has been performed to identify the characteristics of bed-load sediments. After sampling, the weight of the bed load collected in the sample bag was measured in the laboratory and then, the samples were granulated in the laboratory with a number of sieves with different numbering and shaker device. Granulating of bed load samples was done in such a way that the collected samples were mixed together, which included three points in each section and performing three repetitions at each point and a total of 9 samples in each section.

To generate the bed form in the laboratory, fine gravel particles with an average diameter of $3.0 \mathrm{~mm}$ were used. The bed form begins with a section $0.5 \mathrm{~m}$ long horizontally. Afterward, a positive slope (similar lee in dunes) in the flow direction with a slope of $3.45 \%$ with a horizontal length of $1.5 \mathrm{~m}$ connected to a section with no slope (horizontal) and the length of $0.5 \mathrm{~m}$. Next, the bed form continued with a reverse slope (similar to stoss in dune) in the flow direction with a slope of $3.73 \%$ and with a horizontal length of $1.5 \mathrm{~m}$. Figure 3 shows the experimental flume and the profile of the bed form made in the laboratory. 

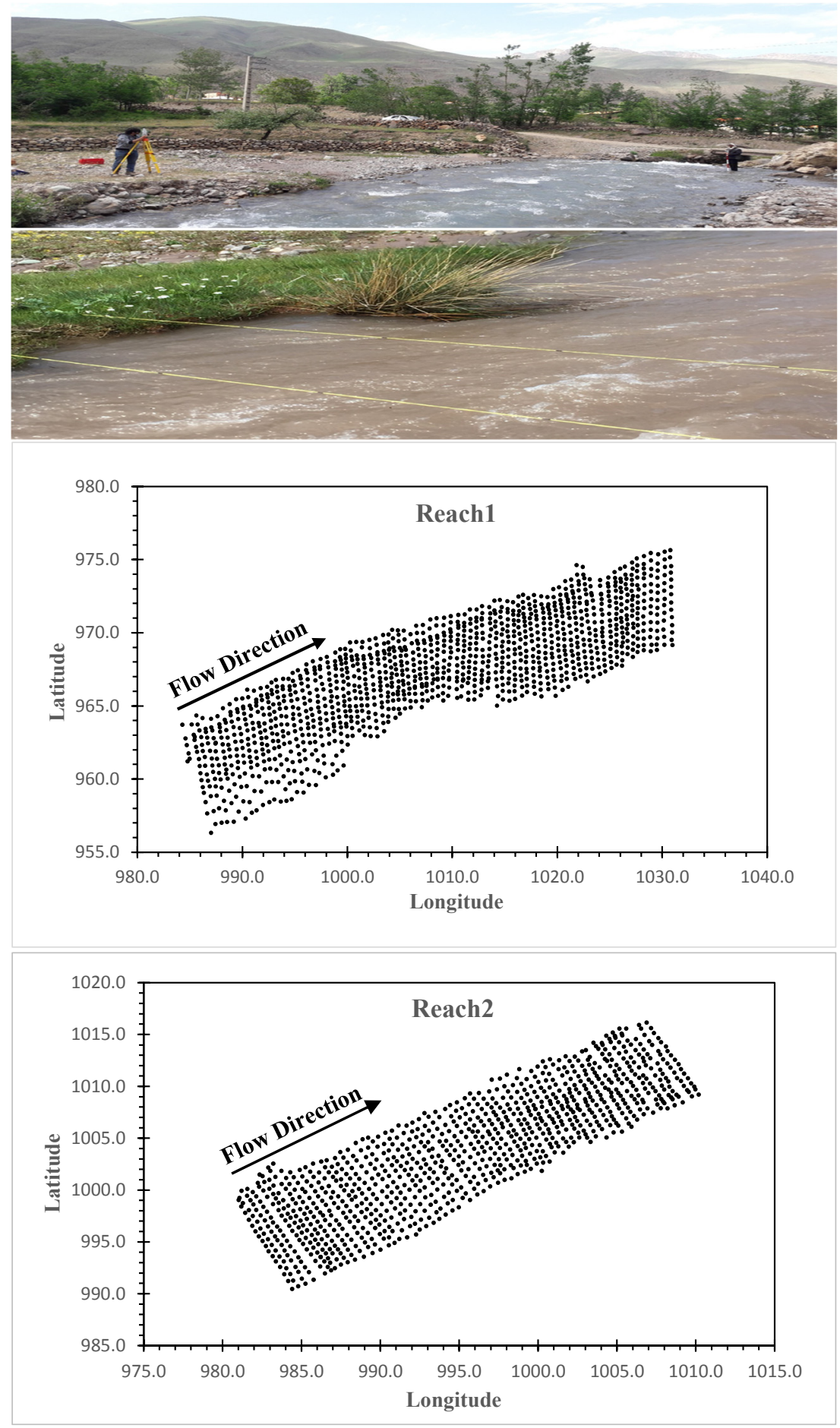

Fig. 4. An image of the riverbed surveying operation and the points surveyed along the riverbed at both reaches.

Table 2. Characteristics of the experiments.

\begin{tabular}{lccccc}
\hline $\begin{array}{l}\text { Test } \\
\text { number }\end{array}$ & Kramer criteria & $\begin{array}{c}\text { Flow discharge } \\
(\text { lit/s) }\end{array}$ & $\begin{array}{c}\text { Number } \\
\text { of sections }\end{array}$ & $\begin{array}{c}\text { Number of velocity } \\
\text { profile in each section }\end{array}$ & $\begin{array}{c}\text { Velocity profile position } \\
\text { in each section }\end{array}$ \\
\hline$(1)$ & Weak motion & 20.2 & 10 & 1 & Flume central axis \\
\hline$(2)$ & Weak motion & 40 & 10 & 1 & Flume central axis \\
\hline$(3)$ & General motion & 21.1 & 10 & 1 & Flume central axis \\
\hline$(4)$ & General motion & 43 & 10 & 1 & Flume central axis \\
\hline
\end{tabular}

Experiments were carried out at 10 cross-sections within a 4.5 -meter reach in the channel. The beginning of the test reach was 6 meters from the entrance of the flume where the flow was fully developed. Experiments were carried out at two depths of 10 and $15 \mathrm{~cm}$, and at each flow depth, two Kramer movement criteria were considered to identify the threshold condition, namely general and weak motion. One type of sediment particle was used in all experiments and 10 sections were used to collect data in which one velocity profile was measured on the central axis of the flume. After reaching the threshold 
condition, based on two criteria of general and weak motion of Kramer, which was done with visual observation, the measurement of velocity profiles was started so that each point velocity was measured with three repetitions and the duration of each repetition was 60 seconds. Table 2 shows the characteristics of experiments. The vertical distance between two point velocities measured near the bed was $0.5 \mathrm{~cm}$ in each profile and then toward the water surface was $1.0 \mathrm{~cm}$. Accordingly, the number of point velocities in each profile, depending on the flow depth, was between 12 and 18 point velocities. After grading the sediment particles used in the laboratory, the values of $d_{16}, d_{50}, d_{84}$ and $d_{90}$ were extracted from the granulation curve and the geometric standard deviation $\left(\sigma_{g}\right)$ of sediment particles, was calculated.

By collecting the coordinates of the riverbed points, it was possible to draw the topographic changes of the riverbed. After drawing the topographic changes of the bed in each reach, it was possible to draw the profile of the bed elevation changes. If the profile is drawn on the central axis and in the flow direction, it will be possible to identify the bed forms and items such as the longitudinal slope and the slope of each cross section. Drawing accurate profiles requires sufficient data, especially at the locations of bed elevation changes. Accordingly, the surveying operation was done carefully on the entire riverbed along the desired reaches. Afzalimehr et al. (2017) applied a type of networking with dimensions of $0.8 \mathrm{~m} \times 0.5 \mathrm{~m}$ in river bed to obtain suitable result; this method was used in this study. In total 1244 points in reach 1 and 981 points in reach 2 were surveyed. Figure 4 shows an image of the riverbed surveying operation and the points surveyed along the riverbed at both reaches.

There are some assumptions and limitations in this study. The flow in the river and laboratory is three-dimensional, although the bed form changes are three-dimensional in the river and two-dimensional in this laboratory work. Construction of the artificial bed forms in the laboratory is nearly similar to observed bed forms in rivers, this has been done by detail surveying in some rivers in Iran. Therefore, the longitudinal slope used in the laboratory is in good agreement with the longitudinal slope due to the topography of the riverbed. One of major limitation in river engineering studies is the measurement of velocity very near the bed. There was no obstacle in river and no vegetation patch was observed in the selected reaches which were used to simulate river and laboratory conditions. Since the relationships in the sources for estimating the threshold conditions in rivers do not provide the same results, it seems that estimating the threshold conditions in each river according to the river type in terms of bed particle size, geometric characteristics, and bedforms, and hydraulic characteristics of flow should be considered. For these reasons the application of Shields parameter to estimate threshold conditions in different rivers leads to different results, in some cases underestimation and in others overestimation of incipient motion of sediment particles. The results can be extended to other rivers by using the same methodology presented in the manuscript, by using simple instrument and applying velocity distribution to calculate the Shields parameter.

\section{CALCULATIONS}

\section{Estimation of Shields parameter}

The following equation was used to calculate the Shields parameter:

$$
\Theta=\frac{\tau_{0}}{\Delta \rho g d} \quad ; \quad \Delta=S-1 \quad ; \quad S=\frac{\rho_{S}}{\rho}
$$

where $\Delta$ is the relative submerged density, $\rho=$ the water density, $\rho_{s}=$ the sediment density, $g=$ the gravitational acceleration, $d=$ the grain size and $\tau_{0}=$ the bed shear stress. To calculate the critical Shields parameter, the critical bed shear stress $\left(\tau_{0 c}\right)$ was used in the above relation. Equation (2) was also used to calculate the bed shear stress, where $u_{*}$ is the shear velocity, which was estimated using the boundary-layer characteristics method.

$\tau_{0}=\rho u_{*}^{2}$

The boundary-layer characteristics method was suggested by Afzalimehr and Anctil (2000) for gravel bed rivers, and extended to Iranian and Canadian rivers by Afzalimehr and Rennie (2009), in which all point velocities in a profile were used to calculate the shear velocity. The shear velocity value in this method was obtained by Equation (3):

$u_{*}=\frac{\left(\delta_{*}-\theta\right) u_{\max }}{c \delta_{*}}$

where $u_{*}$ is the shear velocity, $\delta_{*}$ is the displacement thickness of the boundary layer, $\theta$ is the momentum thickness of boundary layer, $u_{\max }$ is the maximum point velocity measured in each profile, and $c$ is the experimental coefficient, which is a function of flow characteristics and its value from 3.8 to 4.4 was variable. In this study, the value of c was considered to be 4 , which was confirmed by Afzalimehr and Rennie (2009) for gravel bed rivers. The values of $\delta_{*}$ and $\theta$ were also calculated from Equations (4) and (5):

$$
\begin{aligned}
& \delta_{*}=\int_{0}^{h}\left(1-\frac{u}{u_{\max }}\right) \mathrm{d} y \\
& \theta=\int_{0}^{h} \frac{u}{u_{\max }}\left(1-\frac{u}{u_{\max }}\right) \mathrm{d} y
\end{aligned}
$$

\section{Determination of threshold average velocity}

The average flow velocity obtained from the profiles measured in the laboratory was related to the incipient motion, saying they were measured at the threshold conditions. Some relationships were provided by Goncharov (1964), Neill (1968) and Garde (1970) which will be used (Equations 6 to 8) for the comparison of the results with the present study.

$$
\begin{aligned}
& U_{c r}=1.07\left(\Delta g d_{50}\right)^{0.5} \log \left(8.8 \frac{h}{d_{50}}\right) \\
& U_{c r}=1.07\left(\Delta g d_{50}\right)^{0.5}\left(\frac{h}{d_{50}}\right)^{\frac{1}{6}}
\end{aligned}
$$

$U_{c r}=\left(\Delta g d_{50}\right)^{0.5}\left(0.5 \log \frac{h}{d_{50}}+1.63\right)$

In Eqs. (6), (7), and (8) $U_{c r}$ is the cross-sectional threshold average velocity; $U_{c r}=Q_{c r} / b h, \Delta$ is the relative submerged density; $\Delta=S-1, S$ is the relative density; $S=\rho / \rho_{s}$ in which $\rho$ and $\rho_{s}$ are the mass density of water and sediments, respectively, $g$ is the gravitational acceleration, $d_{50}$ is the median sediment size, and $\mathrm{h}$ is the flow depth. 


\section{RESULTS}

Variation of critical bed shear stress with particle size and bed elevation along the selected reaches and laboratory flume

The results of granulation curves consisted of three parts: for particles in the laboratory, in river, and the sampled bed-load particles, presented in Tables 3 to 6 . From the results presented in Tables 4 to 6 , it can be considered that the particles of riverbed and the bed load samples in all sections revealed a geometric standard deviation greater than 1.4, indicating their nonuniform distribution. On the other hand, sediment particles used in the laboratory had a geometric standard deviation of less than 1.4, showing their uniform distribution. Since most gravel bed rivers have non-uniform sediment particles, therefore, all bedload samples show a non-uniform grain distribution. Accordingly, the threshold of motion for non-uniform sediments needs more attention. Investigating the incipient motion of sediments with non-uniform granulation is more complex than with that in uniform sediments, because coarse particles in non-uniform sediments may be more exposed to flow near the bed, therefore they begin to move easily. While fine particles are less exposed to the flow near the bed and they are placed under coarse particles, they move harder and tend to be stable (Dey, 2014). The values of critical bed shear stress for each section were estimated using the diagram of changes in the bed shear stress against the corresponding sediment entrainment rate (in weight per unit time and length) (Table 7). Figure 5 shows how the values of the critical bed shear stress change with bed forms and particle size along the reaches.

From Table 7, it can be seen that the critical bed shear stress values in reach 1 were greater than ones in reach 2 . On the other hand, according to the granulation results in Tables 5 and 6 , the median grain size of bed-load particles in reach 1 was greater than in reach 2 . The higher critical bed shear stress values of reach 1 than ones in reach 2 can be attributed to the factors, such as greater average flow depth of reach 1 than of reach 2 and also the larger median grain size of bed-load particles in reach 1 than in reach 2. From Figures 5 and 6, it can be seen that the variation of critical bed shear stress with the bed elevation in the laboratory channel indicates a more regular trend than does the river. In these Figures, the black dots indicate the locations of the velocity profiles along the river reaches and the flume. With more precision in Figures 5 and 6, it can be seen that in the flume and under general and weak motion, in parts of the flat bed where the bed is completely horizontal, the critical bed shear stress in the flow direction decreases. This declining trend of critical bed shear stress in the flow direction was also observed in parts of the riverbed where a slight slope is prevalent. For example, in reach 1, from section 1 to 2 and in reach 2 , at a distance of $8 \mathrm{~m}$ from the beginning of reach to

Table 3. Specifications of the sediment particles used in the laboratory.

\begin{tabular}{cccccc}
\hline $\begin{array}{c}\text { Particle group } \\
\text { classification }\end{array}$ & $d_{16}(\mathrm{~mm})$ & $d_{50}(\mathrm{~mm})$ & $d_{84}(\mathrm{~mm})$ & $d_{90}(\mathrm{~mm})$ & $\sigma_{g}$ \\
\hline Fine gravel & 2.1 & 3.0 & 4.1 & 4.5 & 1.39 \\
\hline
\end{tabular}

Table 4. Specifications of the particles that make up the river bed.

\begin{tabular}{cccccc}
\hline Reach number & $d_{16}(\mathrm{~mm})$ & $d_{50}(\mathrm{~mm})$ & $d_{84}(\mathrm{~mm})$ & $d_{90}(\mathrm{~mm})$ & $\sigma_{g}$ \\
\hline$(1)$ & 2.2 & 3.2 & 4.5 & 5.0 & 1.43 \\
\hline$(2)$ & 9.0 & 18 & 32 & 35 & 1.88 \\
\hline
\end{tabular}

Table 5. Specifications of the sampled bed-load particles (Reach 1).

\begin{tabular}{cccccc}
\hline Section number & $d_{16}(\mathrm{~mm})$ & $d_{50}(\mathrm{~mm})$ & $d_{84}(\mathrm{~mm})$ & $d_{90}(\mathrm{~mm})$ & $\sigma_{g}$ \\
\hline$(1)$ & 1.1 & 27 & 45 & 48 & 6.39 \\
\hline$(2)$ & 1.5 & 6.0 & 9.0 & 11 & 2.44 \\
\hline$(3)$ & 1.2 & 6.0 & 25 & 34 & 4.56 \\
\hline$(4)$ & 0.9 & 4.0 & 8.0 & 9.0 & 2.98 \\
\hline$(5)$ & 1.1 & 4.9 & 8.9 & 24 & 2.84 \\
\hline Reach1 (General) & 0.9 & 5.4 & 35 & 42 & 6.23 \\
\hline
\end{tabular}

Table 6. Specifications of the sampled bed-load particles (Reach 2).

\begin{tabular}{cccccc}
\hline Section number & $d_{16}(\mathrm{~mm})$ & $d_{50}(\mathrm{~mm})$ & $d_{84}(\mathrm{~mm})$ & $d_{90}(\mathrm{~mm})$ & $\sigma_{g}$ \\
\hline$(1)$ & 1.0 & 6.9 & 27 & 31 & 5.19 \\
\hline$(2)$ & 0.7 & 3.7 & 24 & 29 & 5.85 \\
\hline$(3)$ & 1.3 & 3.7 & 8.0 & 8.5 & 2.48 \\
\hline$(4)$ & 1.7 & 6.1 & 9.0 & 19 & 2.30 \\
\hline$(5)$ & 0.9 & 9.5 & 27 & 31 & 5.47 \\
\hline Reach2 (General) & 0.75 & 3.0 & 20 & 26 & 5.16 \\
\hline
\end{tabular}

Table 7. Critical bed shear stress in river $\left(\mathrm{N} / \mathrm{m}^{2}\right)$.

\begin{tabular}{cccccc}
\hline Section number & $(1)$ & $(2)$ & $(3)$ & & \\
Reach number & & & & \\
\hline$(1)$ & 4.86 & 1.05 & 12.4 & 4.53 & 7.07 \\
\hline$(2)$ & 2.77 & 0.96 & 9.4 & 1.78 & 0.28 \\
\hline
\end{tabular}





Fig. 5. How the values of the critical bed shear stress change with bedforms and particle size along the reaches. (a) Reach 1 and (b) Reach 2.

section 2 , as well as at the distance between sections 3 and 4 , a decreasing trend is observed in the critical bed shear stress. On the other hand, in parts of the laboratory flume that had a positive longitudinal slope in the flow direction and the flow depth in this part increased along with the channel, the critical bed shear stress revealed an increasing variations trend. This showed that in non-uniform decelerating flow, the particles started to move later, which was observed in the laboratory tests. To justify these trends, the following simplified NavierStokes equation is applied:

$\frac{\partial P}{\partial x}=\frac{\partial \tau_{x z}}{\partial z}$

In accelerating flow (over stoss part of bed form), the horizontal velocity $(\mathrm{u})$ increases in the flow direction, therefore, the pressure gradient becomes negative $(\partial P / \partial x<0)$; so, according to Eq. (9), one obtains $\left(\partial \tau_{x z} / \partial z<0\right)$. Moreover, the maximum shear stress occurs at the bed, showing a non-linear concave form toward the water surface. Whereas in decelerating flow the velocity gradient is negative because the velocity decreases in the flow direction, consequently the pressure gradient is positive, $\left(\partial \tau_{x z} / \partial z>0\right)$. Based on Eq. (9), while moving upwards from the bed to the water surface, the shear stress reveals an increasing trend near the bed, and then decreasing trend toward the water surface, showing a non-linear convex form (Afzalimehr et al., 2007; Kironoto et al., 1995; MacVicar and Roy, 2007; MacVicar and Rennie, 2012). The differences between the results observed in the laboratory and the river can be due to factors such as the formation of nonuniform accelerating and decelerating flows in the river and the laboratory flume, meaning that the accelerating and decelerating flows in the laboratory were formed only by applying changes in the bed elevation along with the constant channel width, but in the river, changes in the bed elevation occurred simultaneously with changes in the river width as well. 


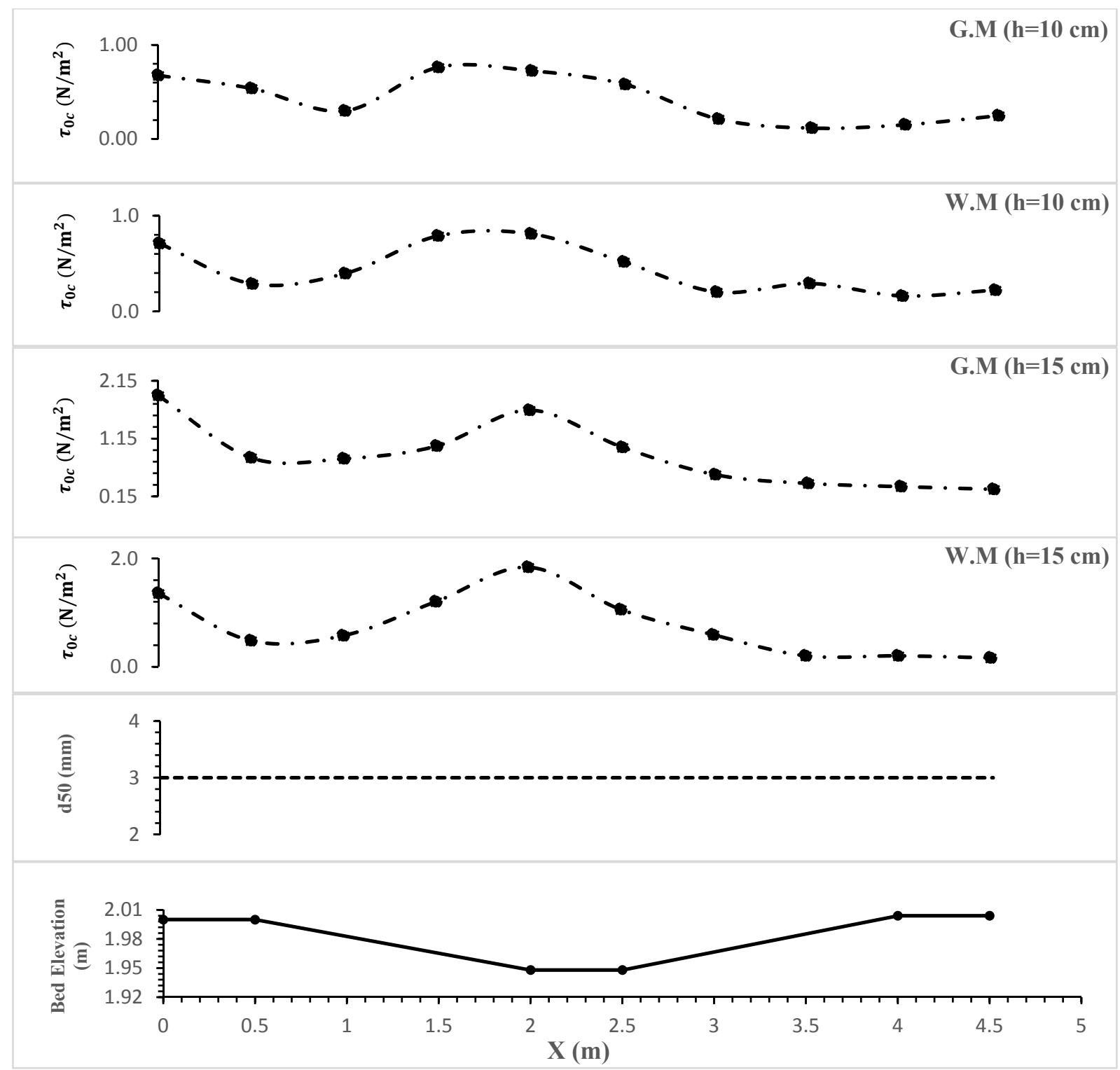

Fig. 6. The critical bed shear stress variations with the bed elevation in the laboratory channel.

The flow was geometrically two-dimensional in the laboratory but three-dimensional in the river. Another reason for the difference between laboratory and river results could be justified that in the river, the bed-load particles had nonuniform grading and $d_{50}$ was different for each section, while the sediment particles used in the laboratory had uniform grading with constant $d_{50}$ along the flume. Keller (1971) stated that as the flow discharge increased, the velocities near the bed in the pool increased faster than the velocities near the bed in the riffle, until at relatively high flow discharge, the velocities near the bed in the pool became greater than the velocities near the bed in the riffle. On the other hand, Hassan and Woodsmith (2004) showed that in lower shear stresses in the pool, the tendency of particles to move was higher than in other parts of the bed form. From Figure 6, it is observed that in all four experimental runs, the bed shear stress in the pool section had a decreasing trend. Also, Figure 6 shows that with increasing the flow discharge, the critical bed shear stress decreasing more. Therefore, as the flow discharge increases, the velocities near the bed in the pool section increase faster and the particles begin to move faster, resulting in a further reduction in critical bed shear stress in this area.

\section{Velocity distribution across the flow depth in the presence of bed form}

Velocity profiles obtained from river measurements show that there are deviations in the velocity distribution across the flow depth, which is different from the distribution of velocity profile in uniform flow. This can be due to the presence of bed form and the formation of non-uniform flows in river. Figure 7 shows the velocity profiles measured in the central axis of the river in reaches 1 and 2. Depending on the location of measurement, the presence of bed forms and the changes in the river width at that location may have produce a specific velocity distribution across the flow depth. With more precision in Figure 7 , it can be seen that in the central velocity profile in section 2 of reach 2 , the maximum velocity was located significantly below the water surface, which can be due to significant reduction in river width and the presence of bedforms in this section, as well as the effect of the transverse slope on the velocity profile. Figure 8 shows the velocity profiles measured in the laboratory, confirming three criteria of non-uniform accelerating and decelerating flows: 1 . The maximum velocity position in the velocity profile was in the decelerating flow at the water 


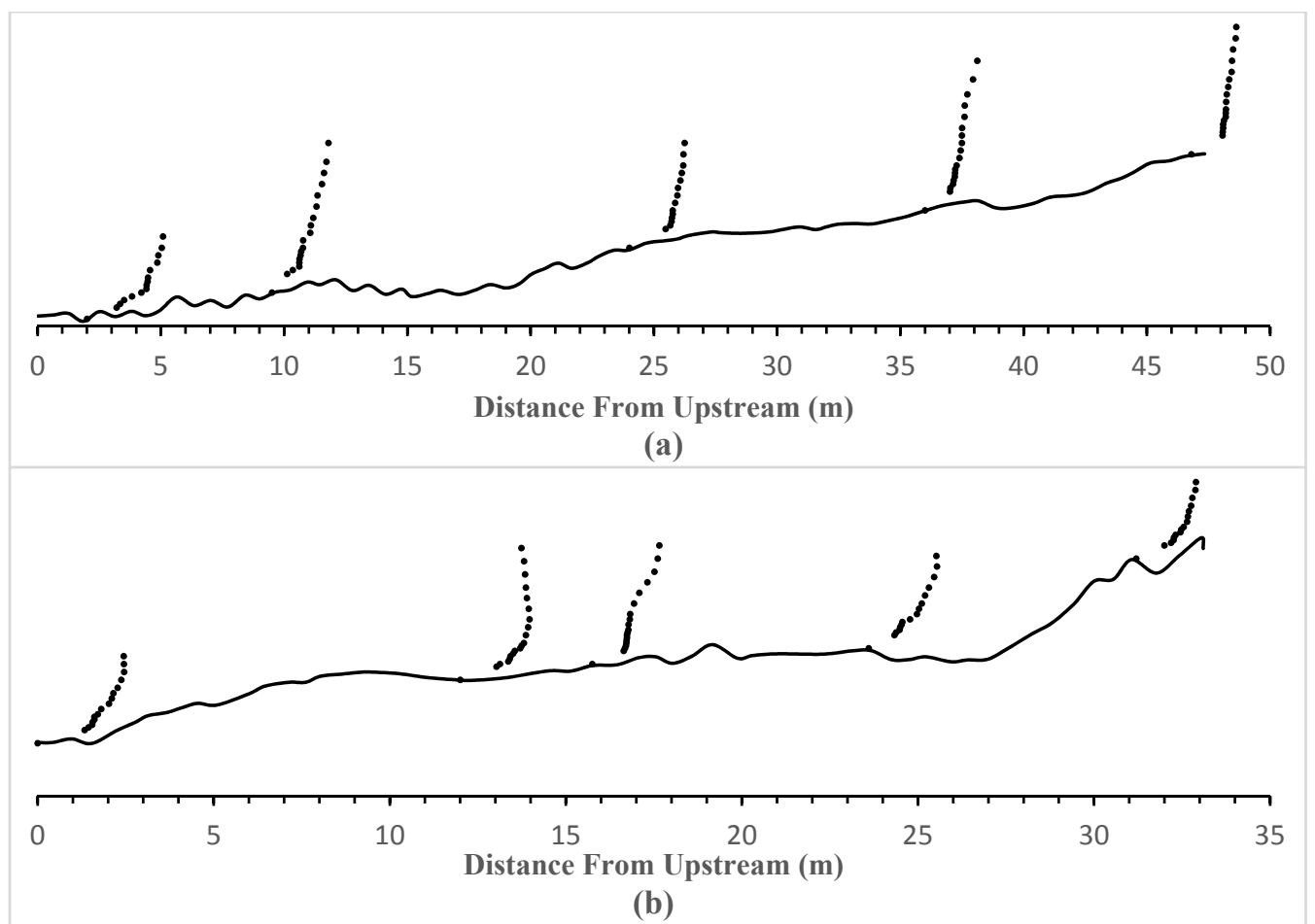

Fig. 7. The velocity profiles measured on the central axis of the river. (a) Reach 1 and (b) Reach 2.

surface and in the accelerating flow below the water surface; 2. The velocity profile in the outer region had a deviation, so that in the decelerating flow the point velocities had higher than those in the accelerating flow; and 3. The Reynolds stress distribution in the accelerating and decelerating flows are concave and convex forms respectively.

\section{Chronological order of incipient motion of the particle under decelerating and accelerating flows}

Using the distribution of shear stress in vertical direction in non-uniform accelerating and decelerating flows, as well as the velocity changes near the bed, the threshold of motion of sediment particles and the chronological order of incipient motion of sediment particles can be examined. In the decelerating flow, due to convex distribution of shear stress in vertical direction, the maximum shear stress occurs at a certain distance from the bed, while in the accelerating flow due to concave shear stress distribution the maximum shear stress occurs in the bed. According to Figure 8, it can be stated that in the accelerating flow, the range of velocity changes near the bed is more than ones in the decelerating flow. Therefore, it can be stated that during the accelerating flow, the sediment particles were affected by this process and compared to other parts of the bed, showing faster moving of sediment particles. Similar behavior was observed from the flow and sediment particles in laboratory. On the other hand, according to the measured velocity profiles in the decelerating flow in the laboratory (Figure 8), it can be seen that the range of velocity variation near the bed is smaller than the accelerating flow. Therefore, the sediment particles in parts of the bed that were under the decelerating flow started to move later, confirming the same behavior observed in the laboratory. However, the motion of sediment particles on the bed with a negative slope (similar to stoss region in dune), due to the drag and weight component forces applied against the flow motion was more difficult than the parts having a positive slope (similar to lee region in dune) in the flow direction. Chartrand et al. (2018) reported that the values of average shear velocity and the flow velocity in each section decrease separately, decreasing the incipient motion in the widening sections (decelerating flow region), and increasing for the narrowing sections of the channel (accelerating flow region). Fazel et al. (2018) stated in their study that the values of average velocity during upstream riffle in the flow direction were generally lower than the downstream riffle and also the maximum value of average velocity in the flow direction occurred in downstream riffle, confirming the findings of the present study.

\section{Average threshold velocity $\left(U_{c r}\right)$}

Since all measurements in the laboratory are performed under threshold conditions, it is possible to achieve an average threshold velocity by averaging each of the measured velocity profiles. Figure $9(a, b)$ shows the trend of average threshold velocity changes during decelerating and accelerating flows with constant $\mathrm{d}_{50}$. From Figure 9(a), it can be seen that with increasing depth in the decelerating flow, the average threshold velocity decreases, while in Figure 9(b) with decreasing depth in the accelerating flow, the average threshold velocity values along the channel increase. It should be noted that in all experimental cases, including weak and general motions with low and high flow discharges, the average threshold velocity changes along the channel under decelerating and accelerating flows were similar to Figure $9(a, b)$. The only difference between the low and high flow discharges was that in high flow discharge, the average threshold velocity was generally higher than low flow one. On the other hand, as can be seen from Figure 9(c), the average threshold velocity values calculated by the Equations (6) to (8) had different trends. Unlike Figure 9(a, b), Figure 9 (c) shows that the average threshold velocity values calculated by these equations increased with increasing depth in the 


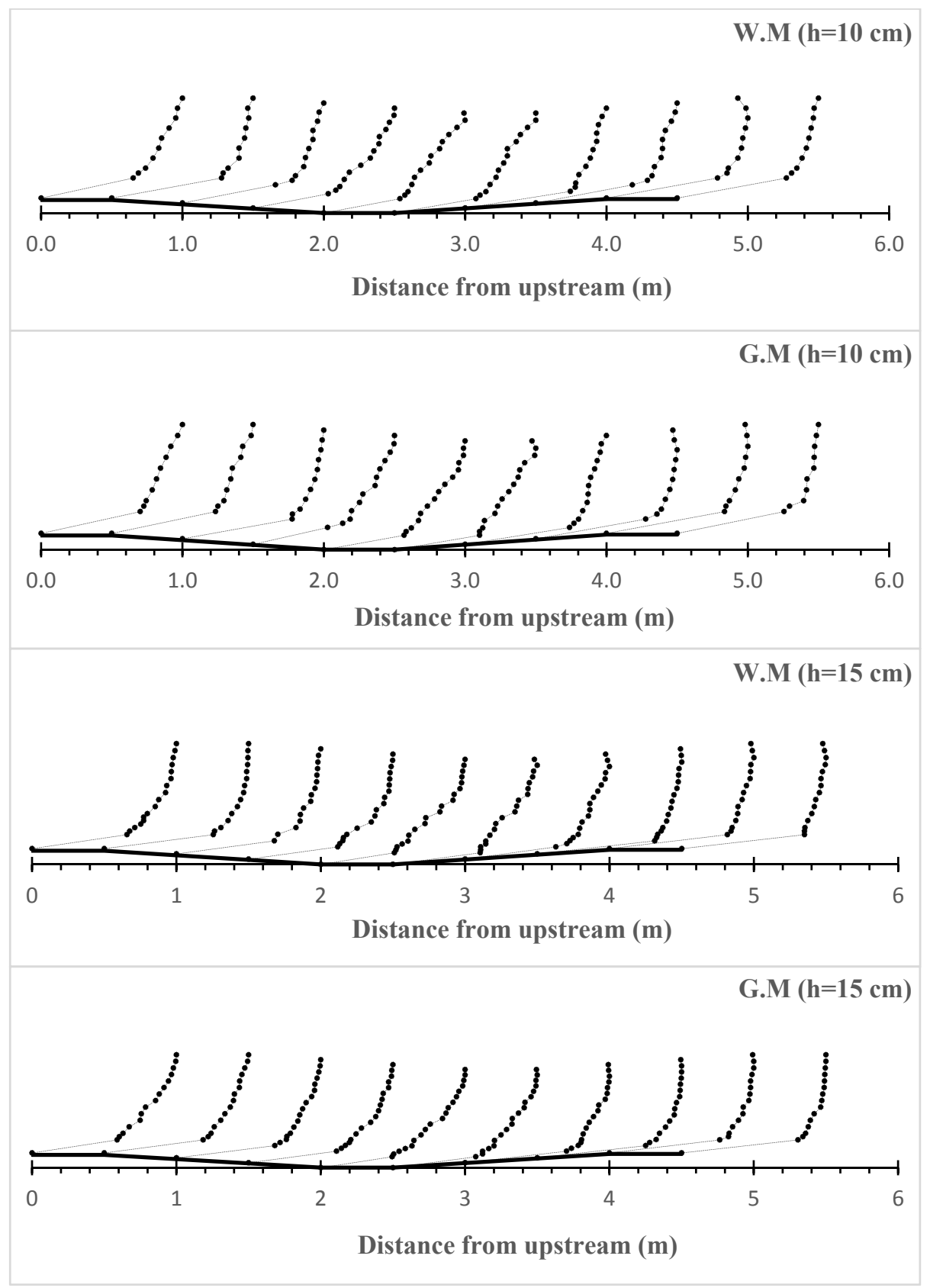

Fig. 8. The velocity profiles measured in the laboratory.

decelerating flow and decreased with decreasing depth in the accelerating flow. The reason can be attributed to the bed form and the formation of non-uniform decelerating and accelerating flows. Shahmohammadi et al. (2018) showed in an experimental study that changes in the average threshold velocity were directly related to changes in flow depth, i.e., similar to Figure 9(c), they also showed that by increasing the flow depth, the average threshold velocity increases. However, their study was performed without the presence of bed form and in a channel over a flat bed. In general, as the flow discharge increased during experiments, the average threshold velocity values increased. The similar results were obtained by comparison of three Equations (6) to (8) and the results of Shahmohammadi et al. (2018). While it was observed that in the channel, with the increasing depth in the decelerating flow, the $U_{c r}$ values decreased and with the decreasing depth in the accelerating flow, the $U_{c r}$ values increased. This is consistent with the explanation for the chronological order of incipient motion of particles in different parts of the bed, which were presented in the previous section. Since $U_{c r}$ changes had a downward trend in the decelerating flow and an upward trend in the accelerating flow, it seems at the first glance that the particles in the decelerating flow started to move faster than the accelerating flow. However, the flow velocity changes depend on the slope (positive or negative) and geometric shape of the cross sections and the type of flow (accelerating or decelerating). This emphasizes that the hydrodynamic forces applied to the particles and their own weight make easier the incipient motion in parts of the bed with a positive slope (decelerating flow), and more difficult in parts of the bed with a negative slope (accelerating flow). However, it should note that due to presence of a positive slope, the changes of velocity values near the bed in decelerating flow are 
(a)

\section{Decelerating Flow}

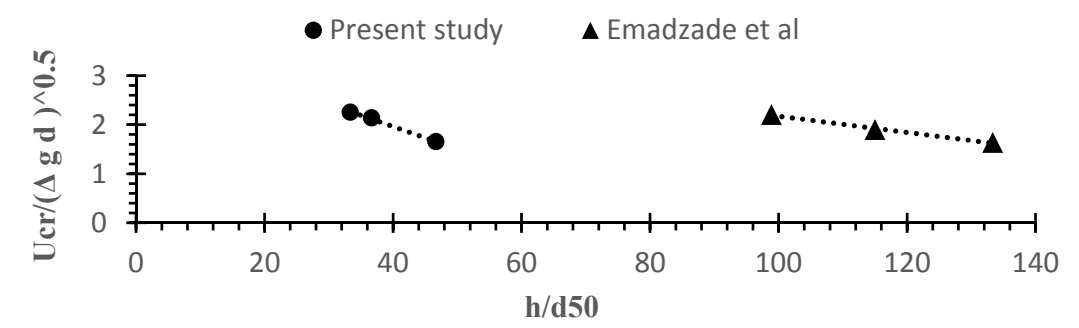

(b)

Accelerating Flow
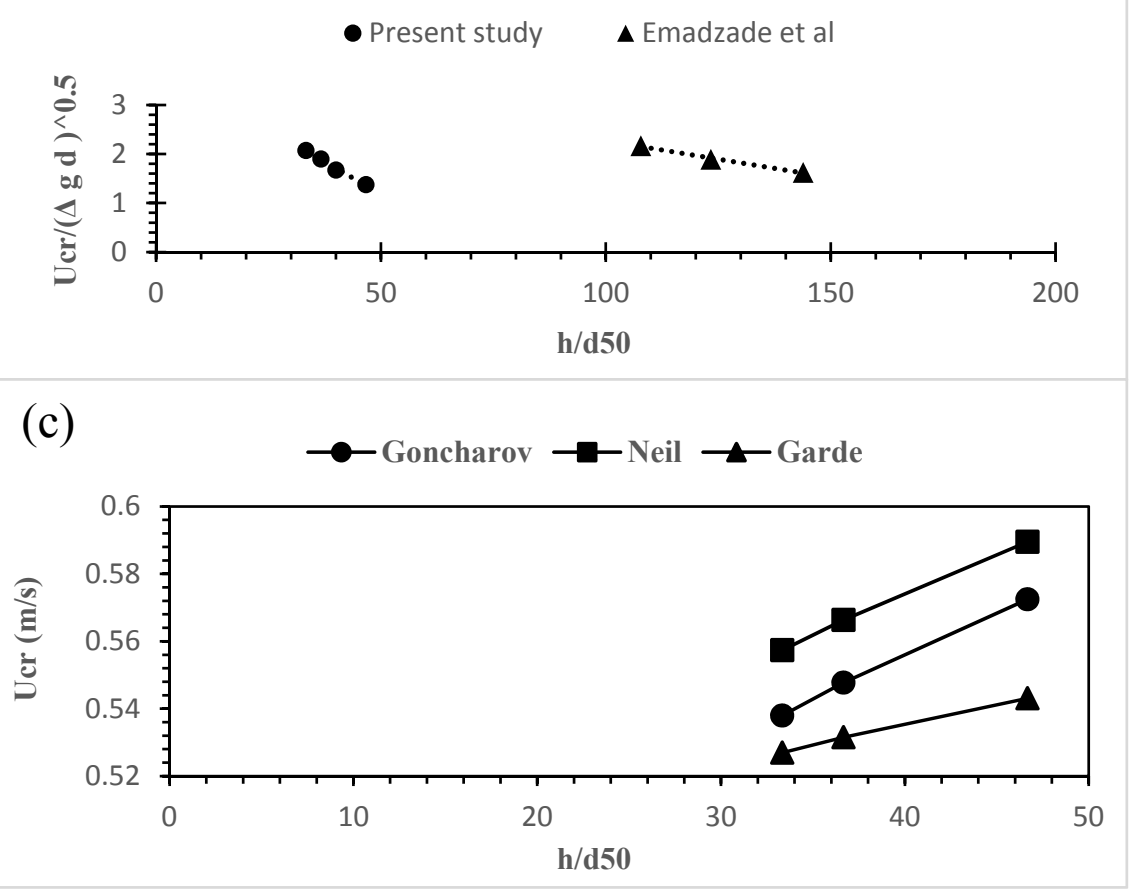

Fig. 9. The trend of average threshold velocity changes (with constant d50). (a) Decelerating flow, (b) Accelerating flow, and (c) Calculated by Equations (6) to (8).

such that the flow reaches the average threshold velocity later, while in the accelerating flow, changes of velocity values near the bed due to the presence of a negative slope are such that the flow velocity increases faster and reaches the threshold value. For this reason, it can be said that the incipient motion occurs earlier and not easier in the accelerating flow (bed with a negative slope) than in the decelerating flow (bed with a positive slope). Comparison with Emadzadeh et al. (2010) results who worked on the effect of accelerating and decelerating flows on incipient motion in sand bed streams, Figure $9(a, b)$ shows an agreement between the results of Emadzadeh el al. (2010) with the present study.

\section{Shields parameter}

Figure 10 shows the values of critical Shields parameter for sections 1 and 2 in reach 1 are significantly below the Shields diagram, indicating no particle movement. However, the movement of particles was observed in these sections. It can observe that the values of the critical Shields parameter for sections 1, 2, 4, and 5 related to reach 2 were below the Shields diagram. For section 5 of reach 1, which had an average diameter size of $4.9 \mathrm{~mm}$, the value of critical Shields parameter in this study was 0.091 . On the other hand, Gilbert (1914) for particles with a median diameter of $4.95 \mathrm{~mm}$, and using the bed load extrapolation method to zero, reported the value of critical Shields parameter equal to 0.089 , was very close to the value presented in this study. Considering the values of critical Shields parameter obtained in the laboratory of this study, presented in Figure 11, it can be seen that the values of the critical Shields parameter obtained by the Shields parameter in both weak and general motion with two different discharges are located below the Shields diagram. In the laboratory, however, the motion of particles was observed in both cases using the visual observation method. Comparing the two diagrams presented in Figure 11, it can be seen that the values of critical Shields parameter increased with increasing the flow discharge and were closer to the Shields diagram. As shown in the diagrams in Figure 11, all values of the threshold Shields parameter were below the Shields diagram, while the particle motion was observed. This could be due to differences in the conditions of Shields' experiments and the hypotheses used in his 


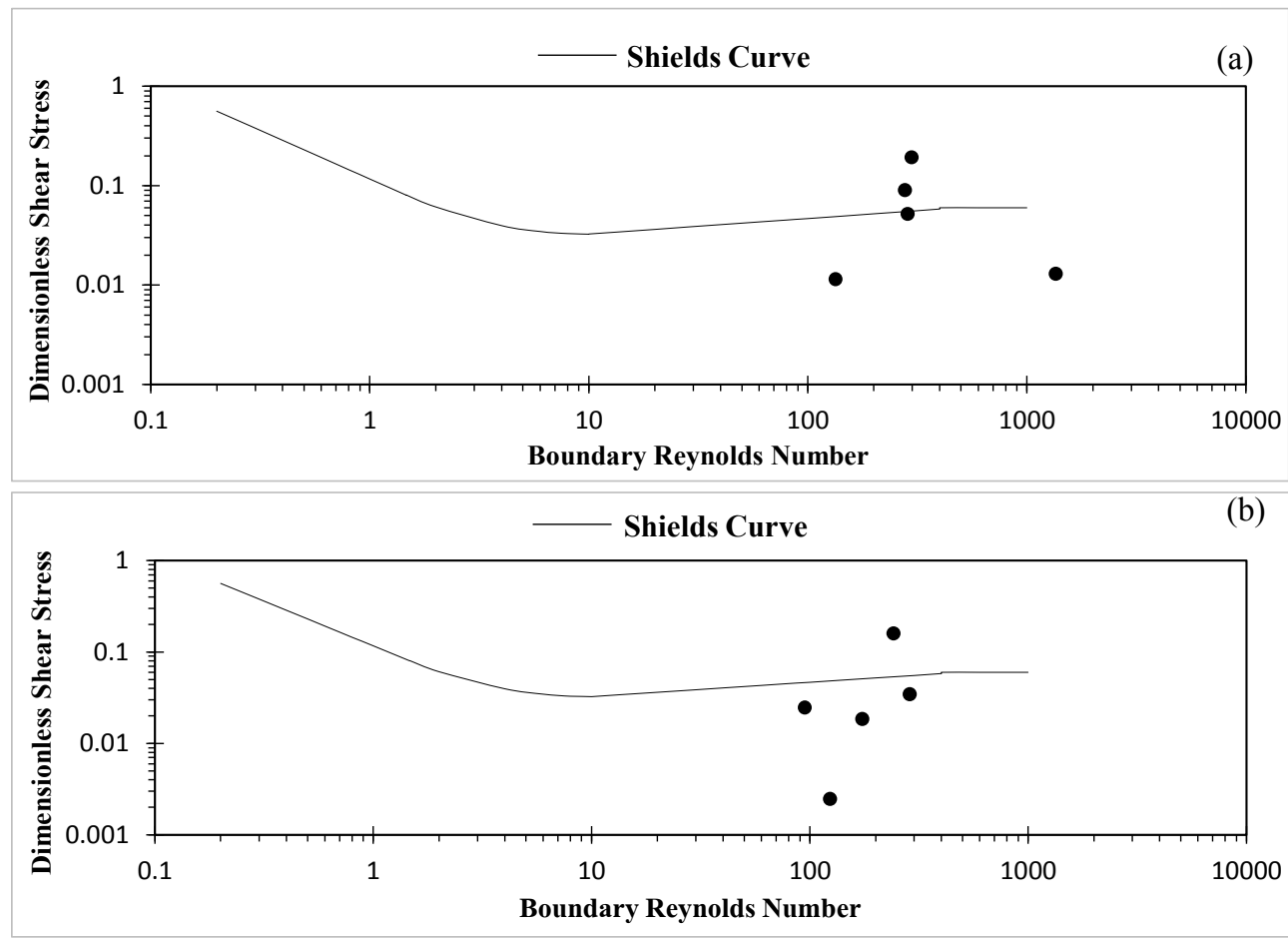

Fig. 10. Shields diagram together with the values of the critical Shields parameter for (a) Reach 1 and (b) Reach 2.

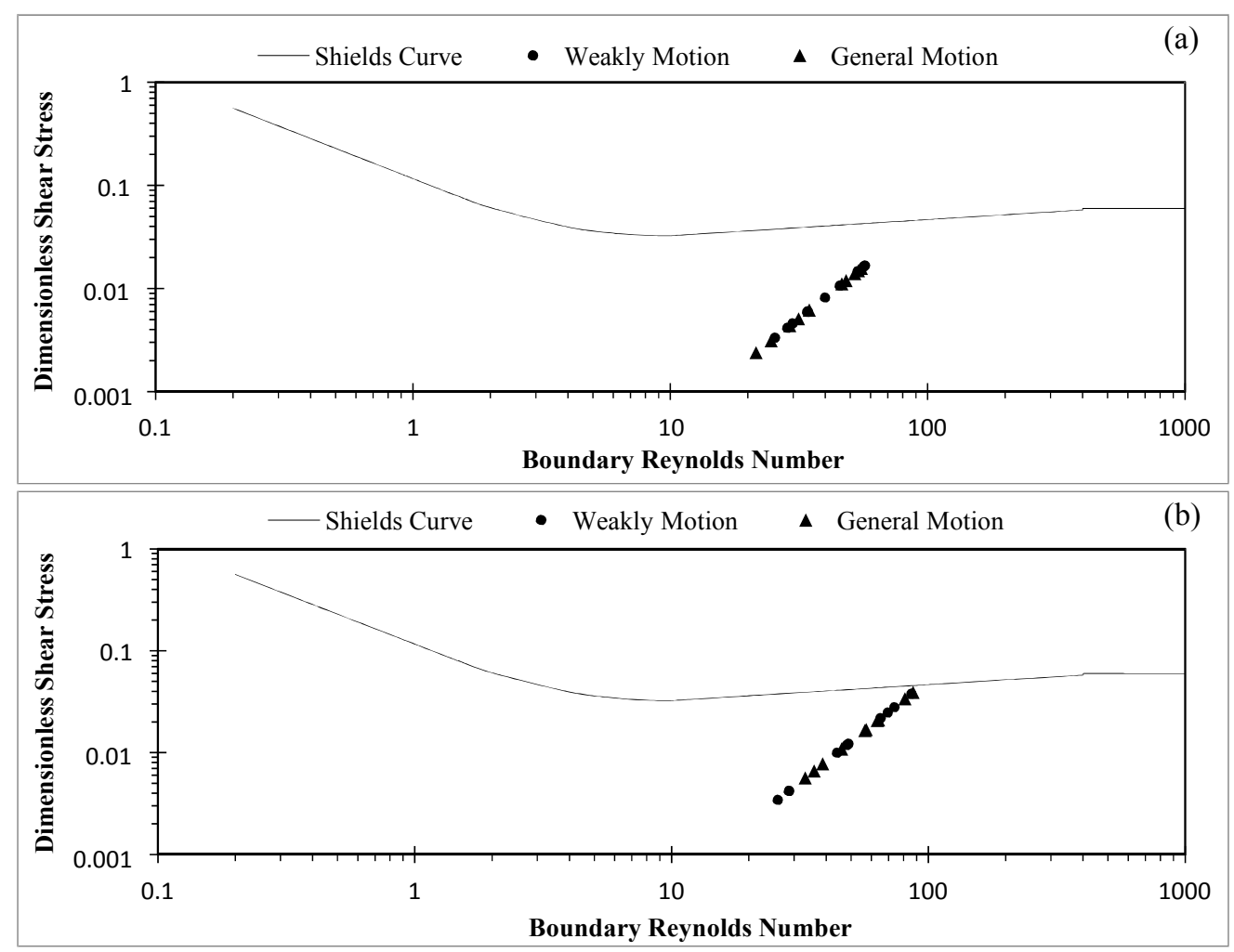

Fig. 11. Shields diagram together with the values of the critical Shields parameter obtained in the laboratory. (a) Depth: $10 \mathrm{~cm}$. (b) Depth: $15 \mathrm{~cm}$.

experiments. Shields used particles with different densities in his experiments, however, in this study, natural fine gravel with a density of $2650 \mathrm{~kg} / \mathrm{m} 3$ was used as sediment particles in laboratory and coarse gravel was used in river. On the other hand, Shields in his study did not consider the effect of bed form in estimating the bed shear stress, which may lead to critical shear stress values higher than actual values.
Nevertheless, the Shields diagram has been widely used as a measure of particle motion threshold. However, as can be seen in this study, and according to the results and discussion in this section, the use of Shields diagram as a criterion for the particle motion threshold, in rivers with different geometric characteristics and non-uniform flows, should be used with caution. 
Incipient motion of sediment particles in the presence of bed forms under decelerating and accelerating flows

Table 8. Critical bed shear stress in the laboratory.

\begin{tabular}{lllllllllll}
\hline Section number & $(1)$ & $(2)$ & $(3)$ & $(4)$ & $(5)$ & $(6)$ & $(7)$ & $(8)$ & $(9)$ & $(10)$ \\
\hline$\tau_{0 c}\left(\mathrm{~N} / \mathrm{m}^{2}\right)$ & 1.9 & 0.8 & 0.8 & 1.0 & 1.6 & 1.0 & 0.5 & 0.4 & 0.3 & 0.3 \\
\hline
\end{tabular}

\section{DISCUSSION}

Most of the rivers or natural channels have complex threedimensional topography with longitudinal and transversal sloping beds in most of their cross sections. This type of sloping bed is especially very common in coarse-bed rivers and meandering rivers. Accordingly, it is important to quantify the shear stress for the incipient motion of sediment on combined sloping beds, applying to both channel beds and banks (Dey, 2003). The changes of the bed slope not only cause a change in the pressure gradient, but also effects on sediment mobility, particularly when the longitudinal bed slope is large. In addition to the effect of longitudinal bed slope on the critical Shields parameter, the flow non-uniformity via the pressure gradient variation also affect the threshold condition. To compare the incipient motion of sand and gravel particles under the uniform and non-uniform flows, the authors found in their other works that in upward slope for accelerating flow inhibits, and downward slope in decelerating flow increases bed sediment mobility. However, the influence of flow accelerating or deceleratinginduced "pressure gradient effect" has an opposite effect on the threshold of bed sediment motion (Afzalimehr et al., 2007; Bolhassani et al., 2015; Emadzadeh et al., 2010) in compared to uniform flow.

This study uses laboratory and river data to investigate the effect of different particle sizes on the incipient motion under non-uniform flows. The authors walked several days in different rivers to find suitable bed forms (which can be modeled in laboratory) where accelerating and decelerating flows are prevalent. In many gravel-bed rivers, the coarse gravel particles are observed as surface layer and the fine particles are located under this layer. Since it was not possible to observe incipient motion of particles in the subsurface layer in data collection period, the fine-gravel particles $\left(d_{50}=3 \mathrm{~mm}\right)$ were investigated in laboratory. The selection of $3 \mathrm{~mm}$ for laboratory is based on field observation. Table 6 also shows that $d_{50}$ of the bed load samples in reach 2 is $3 \mathrm{~mm}$. In addition, when the median particle size becomes more than $2 \mathrm{~mm}$, dunes are rarely observed as dominant bed form in gravel-bed streams. This is why the bed forms were constructed as pool and riffle in laboratory scale. The flow depth in the laboratory in the initial part of pool was 10 and $15 \mathrm{~cm}$ in two runs, which were in agreement with the flow depth in the selected reaches in river. There were several similar conditions between laboratory and river data. For example, in section 2 in reach 1 , the measured velocity profile was taken in $4.16 \mathrm{~m}$ from the right bank, indicating a flow depth of $15 \mathrm{~cm}$, and in section 1 of reach 2, where the measured velocity profile is located $1.2 \mathrm{~m}$ from the right bank, the flow depth was $10 \mathrm{~cm}$. Also, in section 4 of reach 2 , the measured velocity profile was taken in $7.16 \mathrm{~m}$ from the right bank, presenting a flow depth of $15 \mathrm{~cm}$. The relationship between the bed forms in the selected reaches in river and the bed forms made in the laboratory depends on their entrance and exit slopes. Accordingly, positive and negative slopes for the bed form made in the laboratory $(+3.45$ and -3.73$)$ were actually the average of the positive and negative slopes of the river bed forms. In fact, many bed forms were surveyed in the river and after analyzing the surveying data, these slopes were selected as entrance and exit slopes for the laboratory tests. Tables 7 and 8 show that the critical bed shear stress values in the laboratory are lower than those in the river. This is due to coarser gravel and the higher flow velocity in river comparison with finegravel in laboratory. Therefore, for the river case, the critical bed shear stress values and as a result, Shields parameters are higher than those in the laboratory. Hassan et al. (2020) showed that as soon as the surface layer formed, the critical shear stress estimates were $17 \%$ to $36 \%$ greater than the nominal critical Shields parameter value of $\sim 0.045$ for granulated gravels. Also, the results show that less must be emphasized on universal values for incipient motion as Buffington and Montgomery (1997) reported, rather than it must emphasize on defendable values. For example, Emadzadeh et al. (2010) found for $d_{50}=$ $1.3 \mathrm{~mm}$ and $S_{0}=+1.25 \%$ and $h=16 \mathrm{~cm}$, the critical Shields parameter 0.069 for decelerating flow and 0.086 for accelerating flow. Also, Bolhassani et al. (2015) found the critical Shields parameter 0.056 for $d_{50}=3.8 \mathrm{~mm}, h=19.7 \mathrm{~cm}$ and $S_{0}=$ $+1.5 \%$, in decelerating flow. Afzalimehr et al. (2007) reported the critical Shields parameter 0.025 for $d_{50}=8 \mathrm{~mm}, h=15 \mathrm{~cm}$ and $S_{0}=+0.75 \%$. All these studies were conducted in laboratory without any bed form effect. In the present study, for $d_{50}=3$ $\mathrm{mm}, h=16 \mathrm{~cm}$ and $S_{0}=+3.45 \%$ the critical Shields parameter was 0.017 in the decelerating flow $S_{0}=-3.73 \%$ was 0.011 for accelerating flow. The interaction of bed forms and the flow non-uniformity reveals that when the critical Shields parameter is under Shields diagram, the particles move. This is due to variation of pressure gradient along the bed form in nonuniform flow which can be considered in both laboratory and river data. Motamedi et al. (2010) found in a gravel-bed river in central Iran, when the Shields critical parameter is under 0.01 , the movement of particles can occur, although based on the Shields diagram, the particle should be in stable condition. This calls for more research on the incipient motion, considering many environmental effects including bed forms, vegetation, and watershed condition.

\section{CONCLUSION}

This study investigated the incipient motion of sediment particles in decelerating and accelerating flows in the presence of bed forms by using river and laboratory data. The following results are presented by this study:

1) The critical bed shear stress increases in the bed form entrance where the bed has a positive slope in the flow direction (for the pool entrance with decelerating flow) and decreases toward the pool exit where the flow is accelerating.

2) It is observed that in the presence of bed forms, the velocity profiles near the bed indicate larger change in the accelerating flow than those in the decelerating flow. It was observed in section 2 of reach 2 , the sudden narrowing of the river width caused the maximum velocity occur significantly below the water surface. By examining the trend of changes in the average threshold velocity in the laboratory channel, it was seen that in the decelerating flow, the average threshold velocity decreases with increasing depth in the flow direction. While in accelerating flow, the opposite was observed. More generally, in decelerating flow as opposed to accelerating flow, the average threshold velocity in the flow direction increases with increasing ratio $\frac{h}{d_{50}}\left(d_{50}=\right.$ constant $)$. 
3) The application of Shields diagram may not be suitable for non-uniform flow (accelerating and decelerating flows) because when the critical Shields parameter is located below the Shields diagram, the particle motion is observed. Therefore, it can be said that the Shields diagram may not be used as a criterion for estimating the threshold condition of sediment particle in rivers in the presence of bed forms where the effect of pressure gradient and flow non-uniformity are important.

4) This study shows that no universal value is prevalent for the incipient motion, therefore it is better to emphasize on defendable observation, considering the flow conditions and river geometry (river width changes and variation of bed form slope), and deviations from the uniform flow conditions.

\section{REFERENCES}

Afzalimehr, H., Anctil, F., 2000. Accelerating shear velocity in gravel-bed channels. Hydrological Sciences Journal, 45, 1, 113-124.

Afzalimehr, H., Dey, S., Rasoulianfar, P., 2007. Influence of decelerating flow on incipient motion of a gravel-bed stream. Sadhana, 32, 5, 545-559.

Afzalimehr, H., Rennie, C.D., 2009. Determination of bed shear stress in gravel-bed rivers using boundary-layer parameters. Hydrological Sciences Journal, 54, 1, 147-159.

Afzalimehr, H., Maddahi, M.R., Sui, J., 2017. Bedform characteristics in a gravel-bed river. Journal of Hydrology and Hydromechanics, 65, 4, 366-377.

Bolhassani, R., Afzalimehr, H., Dey, S., 2015. Effects of relative submergence and bed slope on sediment incipient motion under decelerating flows. Journal of Hydrology and Hydromechanics, 63, 4, 295-302.

Buffington, J.M., Montgomery, D.R., 1997. A systematic analysis of eight decades of incipient motion studies, with special reference to gravel-bedded rivers. Water Resources Research, 33, 8, 1993-2029.

Chartrand, S.M., Jellinek, A.M., Hassan, M.A., Ferrer-Boix, C., 2018. Morphodynamics of a width-variable gravel bed stream: New insights on pool-riffle formation from physical experiments. Journal of Geophysical Research: Earth Surface, 123, 11, 2735-2766.

Chiew, Y.M., Parker, G., 1994. Incipient sediment motion on non-horizontal slopes. Journal of Hydraulic Research, 32, 5 , 649-660.

Church, M., Hassan, M.A., 2005. Upland gravel-bed rivers with low sediment transport. Developments in Earth Surface Processes, 7, 141-168.

Dey, S., Ali, S.Z., 2019. Bed sediment entrainment by streamflow: State of the science. Sedimentology, 66, 5, 1449-1485.

Dey, S., 2003. Threshold of sediment motion on combined transverse and longitudinal sloping beds. Journal of Hydraulic Research, 41, 4, 405-415.

Dey, S., 2014. Fluvial Hydrodynamics. Springer, Berlin.

Dey, S., Debnath, K., 2000. Influence of streamwise bed slope on sediment threshold under stream flow. Journal of Irrigation and Drainage Engineering, 126, 4, 255-263.

Emadzadeh, A., Chiew, Y.M., Afzalimehr, H., 2010. Effect of accelerating and decelerating flows on incipient motion in sand bed streams. Advances in Water Resources, 33, 9, 1094-1104.

Fazel Najafabadi, E., Afzalimehr, H., Rowiński, P.M., 2018. Flow structure through a fluvial pool-riffle sequence-Case study. Journal of Hydro-environment Research, 19, 1-15.

Garde, R.J., 1970. Initiation of Motion on a hydrody-namically rough surface - Critical velocity approach. Water and Energy International, 27, 3, 271-282.

Gilbert, G.K., 1914. The transportation of debris by running water, (No. 86). US Government Printing Office.

Goncharov, V.N., 1964. Dynamics of Channel Flow. Israel Program for Scientific Translations.

Hassan, M.A., Saletti, M., Johnson, J.P., Ferrer-Boix, C., Venditti, J.G., Church, M., 2020. Experimental insights into the threshold of motion in alluvial channels: Sediment supply and streambed state. Journal of Geophysical Research: Earth Surface, 125, 12, e2020JF005736.

Hassan, M.A., Woodsmith, R.D., 2004. Bed load transport in an obstruction-formed pool in a forest, gravel-bed stream. Geomorphology, 58, 1-4, 203-221.

Keller, E.A., 1971. Areal sorting of bed-load material: the hypothesis of velocity reversal. Geological Society of America Bulletin, 82, 3, 753-756.

Kironoto, B.A., Graf, W.H., Reynolds, 1995. Turbulence characteristics in rough non-uniform open-channel flow. Proceedings of the Institution of Civil Engineers - Water Maritime and Energy, 112, 4, 336-348.

Lamb, M.P., Dietrich, W.E., Venditti, J.G., 2008. Is the critical Shields stress for incipient sediment motion dependent on channel-bed slope? Journal of Geophysical Research: Earth Surface, 113, F2.

Luque, R.F., Van Beek, R., 1976. Erosion and transport of bed-load sediment. Journal of Hydraulic Research, 14, 2, 127-144.

MacVicar, B.J., Rennie, C.D., 2012. Flow and turbulence redistribution in a straight artificial pool. Water Resources Research, 48, 2.

MacVicar, B.J., Roy, A., 2007. Hydrodynamics of a forced riffle pool in a gravel bed river: 1 . Mean velocity and turbulence intensity. Water Resources Research, 43, 12.

Motamedi, A., Afzalimehr, H., Singh, V.J., 2010. Evaluation of a novel approach to determine the critical Shields stress. Journal of Hydrologic Engineering ASCE, 15, 11, 892-900.

Neill, C.R., 1968. Note on initial movement of coarse uniform bed-material. Journal of Hydraulic Research, 6, 2, 173-176.

Shahmohammadi, R., Afzalimehr, H., Sui, J., 2018. Impacts of turbulent flow over a channel bed with a vegetation patch on the incipient motion of sediment. Canadian Journal of Civil Engineering, 45, 9, 803-816.

Shields, A., 1936. Application of similarity principles and turbulence research to bed-load movement. California Institute of Technology, Pasadena, CA. (Unpublished). https://resolver.caltech.edu/CaltechKHR:HydroLabpub167

Wiberg, P.L., Smith, J.D., 1987. Calculations of the critical shear stress for motion of uniform and heterogeneous sediments. Water Resources Research, 23, 8, 1471-1480.

Received 7 May 2021 Accepted 15 October 2021 